\title{
Studies comparing treatment options receive a boost
}

US scientists are trying to answer a question that has long nagged doctors and patients alike: which treatment works best for a given illness?

The US National Institutes of Health will support studies toward an answer, thanks to $\$ 400$ million it received from the economic stimulus package to support research for the next two years on the comparative effectiveness of treatment options for a range of diseases from Alzheimer's to asthma. Such research may, for instance, compare competing drugs or explore the benefits of surgery versus drug therapy. The US Agency for Healthcare Research and Quality and the Department of Health and Human Services will also receive comparable amounts to support comparative effectiveness research.
"The [initiative] will have a tremendous impact on biomedical research in the United States," says Elizabeth Nabel, director of the US National Heart, Lung and Blood Institute. "Our goal is to provide patients, physicians and health care providers evidence-based information to make informed decisions about health care."

Karen Smith, a spokesperson for the drug giant AstraZeneca, stresses that there is already ongoing drug industry research on comparative effectiveness. "You can take any product that's either on the market or in development and say there is an element of comparative effectiveness research that's ongoing not only before but also after we launch it," she says.
But Jerry Avorn, a Harvard Medical School researcher and frequent critic of the pharmaceutical industry, says the government initiative is crucial because drug makers don't always publicize negative findings relating to their bestsellers.

"Had we had comparative testing in the past, several blockbusters would have turned out not to be worthy of their blockbuster status," says Avorn, referring to the arthritis drug Vioxx and the diabetes drug Avandia as two examples. "We learned belatedly that those blockbusters were not only no better but also far less safe than comparable drugs in their class."

Prashant Nair, Chapel Hill, North Carolina

\section{Battle lines drawn as US moves toward generic biologics}

In late March, a bipartisan group of US senators introduced a bill that would open the US market to generic versions of biologic drugs, which have until now been the all-butexclusive province of brand-name makers.

Senator Charles Schumer, the bill's leading sponsor, bemoaned the price tags of biologic drugs, large proteins that are produced by a complicated process involving living cell cultures, rather than straightforward chemistry. Biologic treatments such as Genentech's cancer-fighting antibody Avastin can cost up to $\$ 100,000$ a year. "It's past time we created a way for generic versions of these expensive drugs to come to market," Schumer said a statement.

In Europe such medications are known as 'biosimilars', and a regulatory path opened in 2005 has already brought more than a dozen such drugs to market.

The US senators' bill, known as the Promoting Innovation and Access to LifeSaving Medicine Act, is virtually identical to a recently-introduced House bill whose lead author is Henry Waxman. But these pieces of legislation stand in contrast to a markedly

\section{New center aims to speed drug discovery}

Last month, the UK's Medical

Research Council (MRC) and its related commercialization company, MRC

Technology (MRCT), opened a new center designed to expedite the discovery and development of new drugs. The MRCT Centre for Therapeutics Discovery (CTD) in London opened on 2 April.

With an initial annual operating budget of $£ 7$ million ( $\$ 10$ million), about 70 scientists and 10 scientific \%s support staff will collaborate with outside researchers. They will expand on the work already done by the MRCT Drug Discovery Group, which has focused on developing medicines for diseases with substantial unmet needs. In addition to using computational and medicinal chemistry to produce drugs, scientists at the CTD will work on designing new antibody therapies. Notably, UK scientists can use the MRC's 'Developmental Pathway Funding Scheme' to fund their collaborations with the CTD while still keeping existing intellectual property ownership.

To the knowledge of those at MRC and MRCT, there are no other centers in Europe on the scale of the CTD that will "serve such a wide range of potential diseases" and provide collaboration opportunities for so many researchers, says Justin Bryans, director of Drug Discovery at the center.

Kirsten Dorans, New York more industry-friendly bill also introduced in the House in March by a bipartisan group of lawmakers led by Anna Eshoo with the backing of brand-name biologics makers.

The starkest point of difference is the period of market exclusivity granted to brand-name companies. Under the Waxman and Schumer bills, such companies would be guaranteed at most six years of competition-free market access, whereas Eshoo's version grants them at least 12 years.

Although both bills give the US Food and Drug Administration (FDA) broad discretion to make other key determinations-such as whether costly clinical trials will be required for a generic biologic to win market approval —Eshoo's bill goes further by obliging the agency to go through stringent public procedures when it waives such requirements.

Safety concerns about biologics are far from theoretical. For instance,, a biologic drug for anemia, provoked a near-total shutdown of red blood cell production in scores of patients in Canada and Europe after its manufacturing process was modified $(N$. Engl. J. Med. 346, 469-475; 2002).

The FDA walked a middle line in 2007 Congressional testimony when Janet Woodcock, then the agency's deputy commissioner said that human trials shouldn't be required just for the sake of requiring them. Still, she told lawmakers, given the current state of the science on biosimilars, "we cannot predict the immunogenicity answers without doing human trials."

Meredith Wadman, Washington, DC 